\title{
Pengembangan Perangkat Pembelajaran Matematika dengan Model Discovery Learning Sebagai Upaya Meningkatkan Kemampuan Pemecahan Masalah Matematis Peserta Didik SMP Kabupaten Kampar
}

\author{
Muhammad Abdi ${ }^{1}$, Atma Murni ${ }^{2}$, Sehatta Saragih ${ }^{3}$ \\ ${ }^{1,2,3}$ Program Studi Pendidikan Matematika, Fakultas Keguruan dan Ilmu Pendidikan, Universitas Riau \\ Jl. Bina Widya Simpang Baru, Pekanbaru \\ abdireuss@gmail.com
}

\begin{abstract}
This research is motivated by the low ability of students to solve mathematical problems (KPMM) and apply of learning tools in accordance with the demands of the 2013 curriculum. This device produces learning tools with discovery learning models to improve students' KPMM. The development model used is the 4-D model with validity instruments in the form of syllabus validation sheets, lesson plans, and student worksheets as well as practical instruments in the form of student response questionnaires. Data collection techniques were carried out by distributing questionnaires and observations. Data were analyzed using analysis techniques of validity and analysis of practicality. From the results of data processing, the average validity of the silabus is $96.67 \%$; RPP that is $92.68 \%$; LKPD that is $96.08 \%$. The average student response questionnaire results in the limited trial was $94.04 \%$ with the very practical category. It can be concluded that the learning tools developed have been valid and practical as an effort to improve students' KPMM.
\end{abstract}

Keywords: learning media, discovery learning, mathematical problem-solving ability

\begin{abstract}
Abstrak
Penelitian ini dilatarbelakangi oleh rendahnya Kemampuan Pemecahan Masalah Matematis (KPMM) peserta didik dan menerapkan perangkat pembelajaran yang sesuai dengan tuntutan kurikulum 2013. Perangkat ini menghasilkan perangkat pembelajaran dengan model discovery learning untuk meningkatkan KPMM peserta didik. Model pengembangan yang digunakan adalah model 4-D dengan instrumen validitas berupa lembar validasi silabus, RPP, dan LKPD serta instrumen praktikalitas berupa angket respon peserta didik. Teknik pengumpulan data dilakukan dengan menyebarkan angket dan observasi. Data dianalisis menggunakan teknik analisis kevaliditan dan analisis kepraktisan. Dari hasil pengolahan data diperoleh rata-rata hasil validitas silabus yaitu 96,67\%; RPP yaitu 92,68\%; LKPD yaitu 96,08\%. Rata-rata hasil angket respon peserta didik pada uji coba terbatas adalah 94,04\% dengan kategori sangat praktis. Dapat disimpulkan bahwa perangkat pembelajaran yang dikembangkan telah valid dan praktis sebagai upaya meningkatkan KPMM peserta didik.

Kata kunci: perangkat pembelajaran, model discovery learning, kemampuan pemecahan masalah
\end{abstract}

Copyright (c) 2021 Muhammad Abdi, Atma Murni, Sehatta Saragih

$\square$ Corresponding author: Atma Murni

Email Address: Murni_atma@yahoo.co.id (Jl. Bina Widya Simpang Baru, Pekanbaru)

Received 11 December 2020, Accepted 13 September 2021, Published 17 September 2021

\section{PENDAHULUAN}

Hasil dari The Trend International Matematics and Science Study (TIMSS) tahun 2015 menunjukkan bahwa peserta didik Indonesia berada pada peringkat 45 dari 50 negara di dunia, sejalan dengan itu hasil Program for International Student Assement (PISA) tahun 2015 menujukkan bahwa peserta didik Indonesia menempati peringkat 64 dari 65 negera peserta (OECD, 2013). Faktor yang menjadi penyebab rendahnya prestasi peserta didik Indonesia dalam PISA yaitu lemahnya kemampuan peserta didik dalam memecahkan suatu masalah. Soal yang diujikan dalam PISA terdiri atas 6 level (level 1 terendah dan level 6 tertinggi) dan aspek yang dinilai adalah kemampuan pemahaman, pemecahan masalah, penalaran dan komunikasi. Sedangkan peserta didik Indonesia hanya terbiasa dengan soal-soal rutin pada level 1 dan level 2. 
Dalam NCTM (National Council of Teacher of Mathematics) dinyatakan bahwa pemecahan masalah merupakan proses menerapkan pengetahuan yang telah diperoleh sebelumnya pada situasi baru dan berbeda dengan tujuan membangun matematika baru, memecahkan masalah yang muncul dalam matematika, menerapkan dan menyesuaikan bermacam strategi yang sesuai untuk memecahkan masalah serta membantu dan merefleksikan proses dari pemecahan masalah matematika.

Branca dalam Sumartini (2016) menyatakan bahwa KPMM sangat penting dimiliki oleh setiap peserta didik karena merupakan tujuan umum pengajaran matematika, yang meliputi metode, prosedur dan strategi serta merupakan kemampuan dasar dalam belajar matematika. Selain itu, Ruseffendi (1991) menyatakan bahwa KPMM sangat penting dalam matematika, bukan saja bagi mereka yang dikemudian hari akan mendalami atau mempelajari matematika, melainkan juga bagi mereka yang akan menerapkannya dalam bidang studi lain dan dalam kehidupan sehari-hari. Berdasarkan hal tersebut, KPMM seyogyanya merupakan hasil utama atau target dari pembelajaran matematika. Namun kenyataannya berdasarkan hasil penelitian terdahulu menunjukkan bahwa KPMM masih rendah (Ulya, 2016). Sejalan dengan itu, berdasarkan jawaban ulangan beberapa peserta didik SMP Negeri 4 Tambang diperoleh bahwa peserta didik mempunyai KPMM yang cendrung rendah

NCTM (2000) menyatakan bahwa salah satu tujuan utama pembelajaran matematika sekolah adalah pemecahan masalah (problem solving). Oleh karena itu, guru memiliki peranan yang sangat penting dalam menumbuhkan kemampuan KPMM dalam diri peserta didik, baik dalam bentuk metode pembelajaran yang dipakai, maupun dalam pengembangan perangkat pembelajaran.

Salah satu usaha untuk meningkatkan KPMM adalah dengan menerapkan model pembelajaran yang memberikan kesempatan kepada peserta didik melakukan eksplorasi dan elaborasi dalam pembelajaran untuk meningkatkan pengalaman belajar. Salah satu model yang sejalan dengan ide tersebut adalah model discovery learning. Hal ini sejalan dengan hasil penelitian (Heck, J., \& Dede (2008), Heryani, Y., \& Setialesmana (2017) serta Irsan, I. C., \& Khodra (2016) yang menunjukkan bahwa KPMM meningkat dengan digunakannya model discovery learning dalam pembelajaran.

Menurut Bell (1978) discovery learning merupakan proses belajar yang di dalamnya tidak disajikan suatu konsep dalam bentuk jadi (final), tetapi peserta didik dituntut untuk mengorganisasi sendiri cara belajarnya menemukan konsep. Menurut Hariyanto, T., Rahayu, M., Satria, F., \& Fadhlan, (2019) discovery learning merupakan suatu model pemecahan masalah yang akan bermanfaat bagi peserta didik dalam mengahadapi kehidupan kemudian hari. Lebih lanjut Haeruman et al., (2017) mengungkapkan bahwa model discovery learning, peserta didik tidak langsung mendapat jawaban dari setiap permasalahan, melainkan harus mencarinya sendiri dan melalui proses-proses, dan apabila dalam menjalankan proses-proses tersebut peserta didik menemukan kesulitan-kesulitan, maka mereka dapat menganalisis kembali masalah-masalah yang telah diidentifikasi sehingga dapat menentukan langkah apa yang seharusnya dilakukan agar kesulitan-kesulitan tersebut dapat diatasi.

Berdasarkan penjelasan tersebut, model pembelajaran discovery merupakan suatu model pembelajaran yang menitik beratkan pada aktivitas peserta didik dalam belajar. Didalam proses 
Pengembangan Perangkat Pembelajaran Matematika dengan Model Discovery Learning Sebagai Upaya Meningkatkan Kemampuan Pemecahan Masalah Matematis Peserta Didik SMP Kabupaten Kampar, Muhammad Abdi ${ }^{l}$, Atma Murni, Sehatta Saragih

pembelajaran model discovery learning, guru hanya bertindak sebagai pembimbing dan fasilitator yang mengarahkan peserta didik untuk menemukan konsep, dalil, prosedur, algoritma dan semacamnya. Model pembelajaran discovery learning mengutamakan cara belajar peserta didik aktif, berorientasi pada proses, mengarahkan sendiri, mencari sendiri dan reflektif.

Guru dapat merancang kegiatan pembelajaran dengan model discovery learning yang berisi langkah-langkah untuk meningkatkan KPMM peserta didik, misalnya dalam kegiatan pemberian ransangan, mengidentifikasi masalah, mengumpulkan data, pengolahan data, menverifikasi dan mengeneralisasi. Penerapan keterampilan pemecahan masalah dalam pembelajaran akan membuat peserta didik terbiasa untuk menganalisis dalam menyelesaikan persoalan yang ditemukan.

Agar penerapan suatu model pembelajaran berjalan dengan baik, maka perlu perencanaan pembelajaran yang tepat dan sesuai dengan standar proses yang diterapkan dalam kurikulum. Permendikbud Nomor 22 Tahun 2016 tentang Standar Proses Pendidikan Dasar dan Menengah menyebutkan bahwa standar proses mencakup perencanaan proses pembelajaran, perencanaan pembelajaran dirancang dalam bentuk Silabus dan Rencana Pelaksanaan Pembelajaran (RPP) yang mangacu pada Standar Isi. Selain itu, setiap guru berkewajiban menyusun RPP secara lengkap dan sistematis agar pembelajaran berlangsung secara interaktif, inspiratif, menyenangkan, menantang, efisien, memotivasi peserta didik untuk berpartisipasi aktif, memberi ruang yang cukup bagi prakasa, kreativitas, dan kemandirian sesuai bakat, minat, dan perkembangan fisik serta psikologis peserta didik.

Menurut Sari (2016) menyatakan sebagian besar guru belum mengembangkan perangkat pembelajaran yang sesuai dengan kebutuhan peserta didik. Perangkat pembelajaran yang dibuat guru hanya sekedar formalitas dan tidak menggambarkan kegiatan yang melibatkan aktivitas peserta didik. Hal tersebut dapat terlihat dari hasil observasi yang dilakukan di SMP Negeri 4 Tambang, diperoleh informasi bahwa perangkat pembelajaran yang dibuat guru masih terdapat kelemahan yang perlu diperbaiki. Diantara kelemahannya yaitu dalam penyusunanan RPP yang dikembangkan, indikator pencapain kompetensi berdasarkan KD masih dalam tahap berpikir tingkat rendah serta guru tidak mengembangkan LKPD. Guru masih menggunakan buku pegangan peserta didik dari kemendikbud sebagai satu-satunya bahan sumber dalam belajar.

Berdasarkan kelemahan mengembangkan perangkat pembelajaran dan dalam upaya optimalisasi penerapan kurikulum 2013 yaitu kurangnya sumber belajar yang dikembangkan oleh guru sendiri, maka perlu dikembangkan perangkat pembelajaran untuk membantu guru dalam mengimplementasikan kurikulum 2013. Perangkat pembelajaran yang dikembangkan harus lengkap, baik dari segi kegiatan yang dilakukan peserta didik yang dapat membiasakan dalam menyelesaikan permasalahan matematika dan melibatkan peserta didik secara aktif untuk menyelesaikan masalah dengan strategi-strategi penyelesain yang efektif.

Beberapa penelitian tentang model discovery learning telah diterapkan. Menurut Hendri, S., \& Kenedi (2018) menunjukkan perangkat pembelajaran berbasis discovery learning yang dirancang valid, praktis, dan efektif digunakan untuk meningkatkan KPMM peserta didik. Menurut hasil penelitian Siti 
Hajar \& In'am, (2017) "Discovery learning is proven to improve the quality of learning compored to conventional methods, and learners can improve their knoeledge during the learning process". Maksudnya adalah pembelajaran discovery terbukti dapat meningkatkan kualitas pembelajaran dibandingkan metode konvensional, dan peserta didik dapat meningkatkan pengetahuan mereka selama proses pembelajaran.

Untuk membantu guru mengimplementasikan Kurikulum 2013, dibutuhkan pengembangan perangkat pembelajaran yang valid, praktis dan efektif. Peneliti tertarik untuk mengembangkan perangkat pembelajaran matematika dengan model discovery learning sehingga diperoleh perangkat yang valid dan praktis yang dikembangkan sebagai sarana meningkatkan KPMM peserta didik di kelas VIII SMP.

Nieven dalam Rochmad (2012) menyatakan bahwa perangkat pembelajaran yang dikembangkan dikatakan valid jika perangkat tersebut berdasarkan teori yang memadai dan semua komponen perangkat pembelajaran yang digunakan berhubungan secara konsisten. Secara umum ada tiga pendekatan dalam validitas suatu alat ukur, yaitu validitas isi, konstruks dan kriteria (Suryabrata, 2005). Menurut Trianto (2009) penyusunan LKPD harus memenuhi syarat didaktik, syarat konstruksi, dan syarat teknis. Berdasarkan penjelasan tersebut maka dalam penelitian ini menggunakan empat pendekatan validitas, yaitu validitas isi, validitas konstruks, validitas ditaktis dan validitas teknik. Berdasarkan jenis validasi tersebut, dapat digambarkan pembagian validasi pada silabus, RPP dan LKPD sebagai berikut:

Tabel 1. Validasi Silabus dan RPP

\begin{tabular}{|l|l|l|}
\hline \multicolumn{1}{|c|}{ Perangkat } & Validitas isi & Validitas Konstruks \\
\hline Silabus & Identitas silabus & \multirow{4}{*}{ Kegiatan pembelajaran } \\
\cline { 2 - 2 } & KI dan KD & \multirow{4}{*}{ Kegiatan Pembelajaran } \\
\cline { 2 - 2 } & IPK & \\
\cline { 2 - 2 } & Materi pembelajaran & \\
\cline { 2 - 2 } & Penilaian hasil belajar & \\
\cline { 2 - 2 } & Sumber Belajar & \\
\hline RPP & Identitas RPP & \\
\cline { 2 - 2 } & KI dan KD & \\
\cline { 2 - 2 } & IPK & \\
\cline { 2 - 2 } & Tujuan pembelajaran & \\
\cline { 2 - 2 } & Materi pembelajaran & \\
\cline { 2 - 2 } & KPMM & \\
\cline { 2 - 2 } & Alat, media dan sumber belajar & \\
\cline { 2 - 2 } & Penilaian hasil belajar & \\
\hline
\end{tabular}

Tabel 2. Validasi LKPD

\begin{tabular}{|l|l|}
\hline Aspek Penilaian & \multicolumn{1}{|c|}{ Indikator Penilaian } \\
\hline Isi & Komponen LKPD \\
\cline { 2 - 2 } & Materi pembelajaran \\
\cline { 2 - 2 } & LKPD dan pembelajaran discovery learning \\
\cline { 2 - 2 } & LKPD dan KPMM \\
\hline
\end{tabular}


Pengembangan Perangkat Pembelajaran Matematika dengan Model Discovery Learning Sebagai Upaya Meningkatkan Kemampuan Pemecahan Masalah Matematis Peserta Didik SMP Kabupaten Kampar, Muhammad Abdi ${ }^{l}$, Atma Murni, Sehatta Saragih

\begin{tabular}{|l|l|}
\hline Ditaktis & LKPD dan syarat didaktik \\
\hline Kontruksi & LKPD dan syarat kontruksi \\
\hline Teknis & LKPD dan syarat teknis \\
\hline
\end{tabular}

Sedangkan untuk kepraktisan Novrini (2015) menyatakan bahwa kepraktisan dapat dipenuhi jika ahli dan guru mempertimbangkan perangkat pembelajaran dapat digunakan dan realitanya menunjukkan mudah bagi guru dan peserta didik untuk menggunakan perangkat pembelajaran. Kepraktisan LKPD diperoleh dari angket respon peserta didik dengan indikator penilaian yaitu (1) tampilan dan bahasa, (2) penyajian materi, (3) kegiatan pembelajaran dan (4) manfaat.

\section{METODE}

Penelitian ini merupakan penelitian jenis penelitian pengembangan (Research and Development) dengan model pengembangangan 4-D. Empat tahap dari model pengembangan ini meliputi pendefenisian (define), perancangan (design), pengembangan (develop), dan penyebaran (disseminate). Subjek uji coba adalah peserta didik kelas VIII SMPN 4 Tambang. Instrumen yang digunakan adalah instrumen validitas berupa lembar validitas silabus, RPP dan LKPD serta instrumen praktikalitas berupa angket respon peserta didik. Teknik pengumpulan data dilakukan dengan validasi perangkat pembelajaran untuk mengetahui kevaliditan dan menyebar angket respon peserta didik.

Teknik analisis data yang digunakan adalah analisis kevalidan terhadap lembar validasi untuk mengetahui tingkat kevalidan perangkat pembelajaran yang dikembangkan. Analisis kepraktisan terhadap angket respon peserta didik untuk mengetahui tingkat kepraktisan perangkat pembelajaran yang dikembangkan. Menurut Akbar (2013) produk yang dikembangkan dikatakan layak untuk diuji cobakan jika minimal tingkat kevalidan yang dicapai lebih dari $70 \%$ dengan kategori minimal valid. Adapun kriteria validasi analisis rata-rata yang digunakan dapat dilihat pada Tabel 3 berikut:

Tabel 3. Kriteria Validitas Perangkat Pembelajaran

\begin{tabular}{|l|l|}
\hline \multicolumn{1}{|c|}{ Interval } & \multicolumn{1}{c|}{ Tingkat Validasi } \\
\hline $85,01 \%-100 \%$ & Sangat valid \\
\hline $70,01 \%-85 \%$ & Valid \\
\hline $50,01 \%-70 \%$ & Kurang valid \\
\hline $0,1 \%-50 \%$ & Tidak valid \\
\hline
\end{tabular}

Sedangkan untuk perangkat pembelajaran dapat digunakan jika persentase tingkat keterbacaan lebih dari 70\% dengan kategori minimal praktis. Adapun kriteria berdasarkan hasil praktikalisasi dapat dilihat pada Tabel 4 berikut:

Tabel 4. Kriteria Praktikalitas Perangkat Pembelajaran

\begin{tabular}{|l|l|}
\hline \multicolumn{1}{|c|}{ Interval } & \multicolumn{1}{c|}{ Tingkat Validasi } \\
\hline $85,01 \%-100 \%$ & Sangat Praktis \\
\hline $70,01 \%-85 \%$ & Praktis \\
\hline $50,01 \%-70 \%$ & Kurang Praktis \\
\hline $0,1 \%-50 \%$ & Tidak Praktis \\
\hline
\end{tabular}




\section{HASIL}

Hasil penelitian pengembangan perangkat pembelajaran matematika berupa Silabus, Rencana Pelaksanaan Pembelajaran (RPP), dan Lembar Kerja Peserta Didik (LKPD). Perangkat pembelajaran yang dikembangkan menggunakan model discovery learning pada materi bangun ruang sisi datar kelas VIII SMP. Penelitian ini dilakukan untuk melihat apakah perangkat pembelajaran matematika yang telah dikembangkan memenuhi kategori valid dan praktis dalam upaya meningkatkan KPMM peserta didik. Ada empat tahap yang dilakukan pada penelitian ini sesuai dengan model pengembangan yang digunakan model 4D yaitu define (pendefinisian), design (perancangan), develop (pengembangan), dan disseminate (penyebaran).

Hasil dari tahap pendefinisian yang meliputi analisis awal-akhir, diperoleh informasi bahwa RPP yang dibuat guru belum mencantumkan seluruh komponen yang termuat pada standar proses. Selanjutnya, untuk LKPD yang digunakan masih memakai soal-soal rutin dan tidak kontekstual. Pada tahap analisis peserta didik, berdasarkan hasil ulangan diperoleh informasi bahwa peserta didik masih banyak melakukan kesalahan dalam mengidentifikasi unsur-unsur yang diketahui, peserta didik mengira bahwa alas prisma adalah sisi bawah dari bangun tersebut. Peserta didik juga kurang memahami konsep luas permukaan dan sifat-sifat prisma, sehingga kesulitan atau keliru menerapkan strategi untuk menyelesaikan masalah tersebut.

Selanjutnya pada tahap analisis materi, materi yang dikembangkan adalah materi bangun ruang sisi datar pada KD 3.9 dan 4.9. Peneliti menyusun rencana pelaksanaan pembelajaran menjadi 6 pertemuan seperti pada Tabel 5.

Tabel 5. Rincian Materi Pembelajaran

\begin{tabular}{|c|l|c|}
\hline $\begin{array}{c}\text { Pertemuan } \\
\text { (RPP) }\end{array}$ & \multicolumn{1}{|c|}{ Materi Pembelajaran } & Alokasi Waktu \\
\hline 1 & Luas Permukaan Kubus dan Balok & $3 \mathrm{JP}$ \\
\hline 2 & Volume Kubus dan Balok & $2 \mathrm{JP}$ \\
\hline 3 & Luas Permukaan Prisma & $3 \mathrm{JP}$ \\
\hline 4 & Volume Prisma & $2 \mathrm{JP}$ \\
\hline 5 & Luas Permukaan Limas & $3 \mathrm{JP}$ \\
\hline 6 & Volume Limas & $2 \mathrm{JP}$ \\
\hline
\end{tabular}

Berdasarkan hasil analisis tugas pada materi bangun ruang sisi datar, dapat dirumuskan tugastugas yang harus dilaksanakan peserta didik sebagai berikut:

Tabel 6. Analisis Tugas Pada Materi Bangun Ruang Sisi Datar

\begin{tabular}{|l|l|}
\hline \multicolumn{1}{|c|}{ Materi Pembelajaran } & \multicolumn{1}{c|}{ Tugas-tugas } \\
\hline $\begin{array}{l}\text { Luas pemukaan kubus dan } \\
\text { balok }\end{array}$ & $\begin{array}{l}\text { a. Menghitung luas permukaan kubus dan balok } \\
\text { b. Menyelesaikan masalah yang berkaitan dengan } \\
\text { luas permukaan kubus dan balok }\end{array}$ \\
\hline Volume kubus dan balok & $\begin{array}{l}\text { a. Menghitung volume kubus dan balok } \\
\text { b. Menyelesaikan masalah yang berkaitan denga } \\
\text { volume kubus dan balok }\end{array}$ \\
\hline Luas permukaan prisma & $\begin{array}{l}\text { a. Mengitung luas permukaan prisma } \\
\text { b. Menyelesaikan masalah yang berkaitan dengan } \\
\text { luas permukaan prisma }\end{array}$ \\
\hline
\end{tabular}


Pengembangan Perangkat Pembelajaran Matematika dengan Model Discovery Learning Sebagai Upaya Meningkatkan Kemampuan Pemecahan Masalah Matematis Peserta Didik SMP Kabupaten Kampar, Muhammad Abdi ${ }^{l}$, Atma Murni, Sehatta Saragih

\begin{tabular}{|l|l|}
\hline \multicolumn{1}{|c|}{ Materi Pembelajaran } & \multicolumn{1}{c|}{ Tugas-tugas } \\
\hline Volume prisma & $\begin{array}{l}\text { a. Menghitung volume prisma } \\
\text { b. Menyelesaikan masalah yang berkaitan dengan } \\
\text { volume prisma }\end{array}$ \\
\hline Luas permukaan limas & $\begin{array}{l}\text { a. Menghitung luas permukaan limas } \\
\text { b. Menyelesaikan masalah yang berkaitan dengan } \\
\text { luas permukaan limas }\end{array}$ \\
\hline Volume limas & $\begin{array}{l}\text { a. Menghitung volume limas } \\
\text { b. Menyelesaikan masalah yang berkaitan dengan } \\
\text { volume limas }\end{array}$ \\
\hline
\end{tabular}

Hasil analisis tugas dan analisis materi digunakan untuk merumuskan tujuan pembelajaran. Perumusan tujuan pembelajaran dilakukan untuk mengetahui kajian apa saja yang digunakan dalam menyusun silabus, RPP dan LKPD pada materi bangun ruang sisi datar. Berdasarkan analisis ini diperoleh tujuan-tujuan pembelajaran menggunakan model discovery learning untuk meningkatkan kemampuan pemecahan masalah matematis peserta didik.

Pada tahap perancangan, peneliti mendesain pembelajaran dan membuat rancangan awal perangkat pembelajaran yang dikembangkan yaitu silabus, RPP dan LKPD. Kemudian dilakukan perancangan perangkat pembelajaran, setelah perangkat pembelajaran selesai dirancang, dilakukan pengembangan perangkat pembelajaran dan validasi oleh ahli. Berdasarkan penilaian validator diperoleh fakta terkait dengan validitas perangkat pembelajaran. Berikut ini disajikan hasil analisis validasi silabus, RPP, dan LKPD yang dideskripsikan dalam bentuk tabel secara berturut-turut pada Tabel 7, 8 dan 9 berikut.

Tabel 7. Hasil Validator pada Silabus

\begin{tabular}{|c|c|c|}
\hline Validator 1 & Validator 2 & Validator 3 \\
\hline $93,48 \%$ & $92,39 \%$ & $96,74 \%$ \\
\hline
\end{tabular}

Berdasarkan Tabel 7, diperoleh info bahwa total rata-rata keseluruhan hasil validasi silabus yang dikembangkan mencapai $96,67 \%$ dengan kategori "sangat valid". Hal ini berarti silabus yang dikembangkan sudah sesuai dengan komponen silabus pada Permendikbud Nomor 22 Tahun 2016. Namun demikian, terdapat beberapa saran perbaikan dari validator, yaitu media atau alat peraga yang digunakan dicantumkan dalam silabus, KD pada silabus cukup ditulis satu kali, pendekatan saintifk pada kegiatan pembelajaran diuraikan secara rinci untuk memermudah peneliti dalam mengembangkan RPP. Hal ini dikarenakan silabus merupakan acuan dalam pengembangan RPP (Rusman, 2013).

Tabel 8. Hasil Validator pada RPP

\begin{tabular}{|c|c|c|c|c|c|}
\hline RPP-1 & RPP-2 & RPP-3 & RPP-4 & RPP-5 & RPP-6 \\
\hline $91,93 \%$ & $90,24 \%$ & $91,56 \%$ & $93,44 \%$ & $93,65 \%$ & $95,24 \%$ \\
\hline
\end{tabular}

Berdasarkan Tabel 8, diperoleh info bahwa total rata-rata keseluruhan hasil validasi RPP yang dikembangkan mencapai $91,08 \%$ dengan kategori "sangat valid". Hal ini berarti RPP yang dikembangkan sudah sesuai dengan komponen RPP pada Permendikbud Nomor 22 Tahun 2016. Namun 
demikian, terdapat beberapa saran perbaikan dari validator, yaitu pada indikator pencapaian kompetensi harus sesuai dengan KKO dan pemilihan gambar yang tepat.

\begin{tabular}{|c|c|c|c|c|c|}
\hline $\mathbf{L K}$ & & & & & \\
\hline $91,09 \%$ & $9576 \%$ & $9641 \%$ & $0760 \%$ & $0782 \%$ & $0722 \%$ \\
\hline
\end{tabular}

Berdasarkan Tabel 9, diperoleh info bahwa total rata-rata keseluruhan hasil alidasi LKPD yang dikembangkan mencapai $93,78 \%$ dengan kategori "sangat valid". Hal ini berarti LKPD yang dikembangkan sudah memenuhi syarat-syarat LKPD yang baik. Menurut Nurhayati, F., Widodo, J., \& Soesilowati (2015) menyatakan bahwa LKPD yang disusun memiliki kualitas yang baik apabila memenuhi telah memenuhi syarat isi, didaktik, konstruksi, dan teknis. Namun demikian, terdapat beberapa saran perbaikan dari validator, yaitu permasalahan dalam LKPD harus kontekstual, penggunaan bahasa atau pemilihan kata yang kurang sesuai dengan tingkat berpikir peserta didik, pemilihan gambar serta penggunaan bahasa yang menimbulkan makna ganda.

Ujicoba perangkat pembelajaran dilakukan dengan ujicoba terbatas yang dilakukan pada 8 orang peserta didik. Berdasarkan hasil angket respon peserta didik terhadap LKPD diperoleh rata-rata persentase 94,04\% dengan kriteria sangat praktis, artinya LKPD sudah dapat dipahami oleh peserta didik dari segi masalah yang diberikan, kalimat perintah dalam melakukan kegiatan dan soal latihan. Dengan demikian, perangkat pembelajaran dengan model discovery learning dapat memfasilitasi guru dan peserta didik dalam upaya meningkatkan KPMM matematis peserta didik.

\section{KESIMPULAN}

Berdasarkan hasil validasi terhadap silabus, RPP dan LKPD untuk materi bangun ruang sisi datar dapat disimpulkan bahwa perangkat pembelajaran yang dikembangkan telah memenuhi kriteria valid. Berdasarkan angket respon peserta didik dapat disimpulkan bahwa perangkat pembelajaran yang dikembangkan telah memenuhi kriteria praktis. Dapat disimpulkan bahwa perangkat pembelajaran yang dikembangkan dapat digunakan dalam upaya meningkatkan KPMM peserta didik.

\section{REFERENSI}

Akbar, S. D. (2013). Instrumen Perangkat Pembelajaran. PT Remaja Rosdakarya.

Bell, F. H. (1978). Teaching and learning mathematics (in secondary schools). WC Brown Company. Haeruman, L. D., Rahayu, W., \& Ambarwati, L. (2017). Pengaruh Model Discovery Learning Terhadap Peningkatan Kemampuan Berpikir Kritis Matematis Dan Self-Confidence Ditinjau Dari Kemampuan Awal Matematis Siswa Sma Di Bogor Timur. Jurnal Penelitian Dan Pembelajaran Matematika, 10(2), 157-168. https://doi.org/10.30870/jppm.v10i2.2040

Hariyanto, T., Rahayu, M., Satria, F., \& Fadhlan, M. Y. (2019). Improving Temperature Sensor Accuracy in the IoT Trainer Kit by Linear Regression Method. In 2019 International Conference on Mechatronics, Robotics and Systems Engineering (MoRSE), (pp. 237-240). IEEE. 
Pengembangan Perangkat Pembelajaran Matematika dengan Model Discovery Learning Sebagai Upaya Meningkatkan Kemampuan Pemecahan Masalah Matematis Peserta Didik SMP Kabupaten Kampar, Muhammad Abdi ${ }^{l}$, Atma Murni, Sehatta Saragih

Heck, J., \& Dede, M. (2008). Ferrocene-Based Electro-Optical Materials. John Wiley \& Sons, Ltd: England.

Hendri, S., \& Kenedi, A. K. (2018). Pengembangan perangkat pembelajaran matematika berbasis discovery learning untuk meningkatkan kemampuan pemecahan masalah siswa kelas VIII SMP. Jurnal Inspirasi Pendidikan, 8(2), 10-24.

Heryani, Y., \& Setialesmana, D. (2017). Penggunaan Model Discovery Learning terhadap Peningkatkan Kemampuan Koneksi dan Komunikasi Matematik. Jurnal Pendidikan Matematika, 8(1), 43-52.

Irsan, I. C., \& Khodra, M. L. (2016). Hierarchical multilabel classification for Indonesian news articles. In 2016 International Conference On Advanced Informatics: Concepts, Theory And Application (ICAICTA), (pp. 1-6). IEEE.

NCTM. (2000). Principles and Standars for School Mathematic. VA:NCTM.

Novrini, P. S. \& E. S. (2015). Pengembangan Perangkat Pembelajaran Berorientasi Problem Based Learning untuk Meningkatkan Kemampuan Visual Thinking Dalam Pemecahan Masalah Matematis Siswa Kelas VIII SMP. Jurnal Paradigma, 8 (3).

Nurhayati, F., Widodo, J., \& Soesilowati, E. (2015). Pengembangan LKS berbasis problem based learning (PBL) pokok bahasan tahap pencatatan akuntansi perusahaan jasa. Journal of Economic Education.

OECD. (2013). Results: What Students Know and Can Do: Student Performance in Mathematics, Reading and Science. Paris: PISA- OECD Publishing., 1.

Rochmad. (2012). Desain Model Pengembangan Perangkat Pembelajaran Matematika. Kreano: Jurnal Matematika Kreatif-Inovatif, 3(1), 59-72. https://doi.org/10.15294/kreano.v3i1.2613

Ruseffendi, E. T. (1991). Pendidikan Matematika 3. Depdikbud.

Rusman. (2013). Metode-Metode Pembelajaran: Mengembangkan. Profesionalisme Guru. PT RajaGrafindo Persada.

Sari, W. R. (2016). Pengembangan Perangkat Pembelajaran Bangun Ruang Di Smp Dengan Pendekatan Pendidikan Matematika Realistik. Jurnal Riset Pendidikan Matematika, 3(1), 109. https://doi.org/10.21831/jrpm.v3i1.10407

Siti Hajar, \& In'am, A. (2017). Learning Geometry through Discovery Learning Using a Scientific Approach. International Journal of Instruction, 10(1), 55-70.

Sumartini, T. S. (2016). Peningkatan kemampuan pemecahan masalah matematis siswa melalui pembelajaran berbasis masalah. Mosharafa:Jurnal Pendidikan Matematika, 5(2), 148-158.

Suryabrata, S. (2005). Metodologi Penelitian. Raja Grafindo persada.

Trianto. (2009). Mendesain Model Pembelajaran Inovatif-Progresif. Kencana Prenada Media Group.

Ulya, H. (2016). Profil Kemampuan Pemecahan Masalah Siswa Bermotivasi Belajar Tinggi Berdasarkan Ideal Problem Solving. Jurnal Konseling Gusjigang, 2(1), 274-282. 